\title{
Axial torsion of Meckel's diverticulum causing acute peritonitis in the first trimester of pregnancy: a case report
}

\author{
Hiromitsu Nagata* ${ }^{*}$, Hiroyasu Nishizawa, Susumu Mashima and Yasuyuki Shimahara
}

\begin{abstract}
Background: Meckel's diverticulum is considered the most prevalent congenital anomaly of the gastrointestinal tract. Approximately $4 \%$ of patients are symptomatic with complications such as bleeding, intestinal obstruction, and inflammation, while axial torsion of Meckel's diverticulum is rare, particularly in pregnancy.

Case presentation: A 31-year-old woman in week 15 of pregnancy complained of epigastric pain, nausea and vomiting. Clinical diagnosis was severe hyperemesis gravidarum. Because the symptoms persisted during hospitalization, CT was performed and revealed dilated small bowel loops with multiple air-fluid levels. In the right mid-abdomen, there was a large part of air containing a cavity connected to the small intestine, which was considered a dilated bowel loop. Emergency laparotomy was performed and axial torsion of a large Meckel's diverticulum measuring $11 \mathrm{~cm}$ was found at a few centimeters proximal to the ileocecal valve. lleocecal resection including Meckel's diverticulum was performed. The postoperative course was uneventful. At 40 weeks gestation, she had vaginal delivery of normal baby.

Conclusion: The physiological and anatomical changes in pregnancy can make a straightforward clinical diagnosis difficult. Prompt diagnosis and management were needed in order to avoid significant maternal and fetal risks. The use of imaging examinations, especially $C T$ examination, with proper timing may be helpful to prevent delay in diagnosis and surgical intervention. Here, we report the case of a patient with axial torsion of Meckel's diverticulum in pregnancy. To our knowledge, axial torsion of Meckel's diverticulum in the first trimester of pregnancy has not been reported in the English medical literature.
\end{abstract}

Keywords: Meckel's diverticulum, Axial torsion, Pregnancy, Acute peritonitis

\section{Background}

Meckel's diverticulum (MD) is considered the most prevalent congenital anomaly of the gastrointestinal tract, affecting $2 \%$ of the population $[1,2]$. MD is a true diverticulum of the small bowel, typically found within $100 \mathrm{~cm}$ proximal to the ileocecal valve. It results from incomplete obliteration of the omphalomesenteric duct [3]. Only $4 \%$ of patients with an MD develop complications such as bleeding, perforation, inflammation, and obstruction [4]. Axial torsion of MD is a rare complication [5-7]. Torsion of MD is the result of axial twisting around its base. The exact mechanism for this is unclear.

\footnotetext{
* Correspondence: nagatah@jcho-koriyama.jp

Department of Surgery, Yamatokoriyama Hospital, 1-62 Asahichou, Yamatokoriyama, Nara 639-1013, Japan
}

The degree of torsion varies and can compromise diverticular circulation, leading to necrosis and perforation [8]. We hereby report a very rare case of axial torsion of MD in pregnancy.

\section{Case presentation}

A 31-year-old woman in week 15 of pregnancy with preexisting hyperemesis gravidarum complained of epigastric pain, nausea and vomiting. The patient had undergone a laparoscopic rt. ovarian cystectomy at 30 years old. The patient was hemodynamically stable with a temperature of $36.5^{\circ} \mathrm{C}$, pulse rate of $85 / \mathrm{min}$, respiratory rate of $16 / \mathrm{min}$, blood pressure of 101/52 $\mathrm{mmHg}$ and oxygen saturation of $100 \%$ on room air. The patient's consciousness level was normal. The palpation of the abdomen revealed moderately hard and tender with rebound tenderness at the right 
upper quadrant. Laboratory examination demonstrated

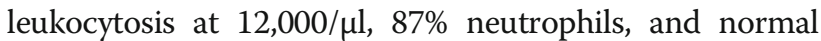
hemoglobin, electrolytes, creatinine, AST, amylase, and Creactive protein. The patient was first diagnosed with severe hyperemesis gravidarum and was admitted.

Thereafter, the patient was commenced on trial of conservative treatment, including intravenous rehydration, antiemetics, and antibiotics. However, the patient presented with persistent abdominal pain. Thirty hours after the admission, laboratory examination demonstrated leukocytosis at 18,000/ $\mathrm{ll}, 93.5 \%$ neutrophils, C-reactive protein of $13.7 \mathrm{mg} / \mathrm{dl}$, fibrin/fibrinogen degradation products at $12.2 \mu \mathrm{g} / \mathrm{ml}$ (normal range, $0.0-5.0 \mu \mathrm{g} / \mathrm{ml}$ ), D-dimer levels of $4.7 \mu \mathrm{g} / \mathrm{ml}$ (normal range, $0.0-1.0 \mu \mathrm{g} / \mathrm{ml}$ ), base excesses of $-4.5 \mathrm{mmol} / \mathrm{l}$ (normal range, $-2.5-2.5 \mathrm{mmol} / \mathrm{l}$ ), and nearly normal hemoglobin, electrolytes, creatinine, AST, and amylase. CT imaging of the abdomen revealed dilated small bowel loops with multiple air-fluid levels; in the right mid-abdomen, there was a large part of air containing cavity connected to the small intestine, which was considered a dilated bowel loop (Fig. 1). As acute peritonitis and strangulated ileus were diagnosed, an emergency laparotomy was planned. The peritoneal cavity was filled with a seropurulent fluid. Further exploration revealed a black and gangrenous $\mathrm{MD}$, with axial torsion, measuring $11 \times 8 \times 5 \mathrm{~cm}$, located $2 \mathrm{~cm}$ proximally to the ileocecal valve (Fig. 2). The ileocecal resection including MD was performed (Fig. 3). Postoperative histopathologic examination confirmed gangrene of MD without neoplasms. The patient recovered uneventfully and was discharged on the 16 th postoperative day. At 40 weeks gestation, she had vaginal delivery of a normal baby.

\section{Discussion}

This case report presents an extremely rare case of giant MD with torsion in pregnancy. A search of the English literature revealed only one case in the third trimester of pregnancy [9]. The etiology of the axial torsion of MD

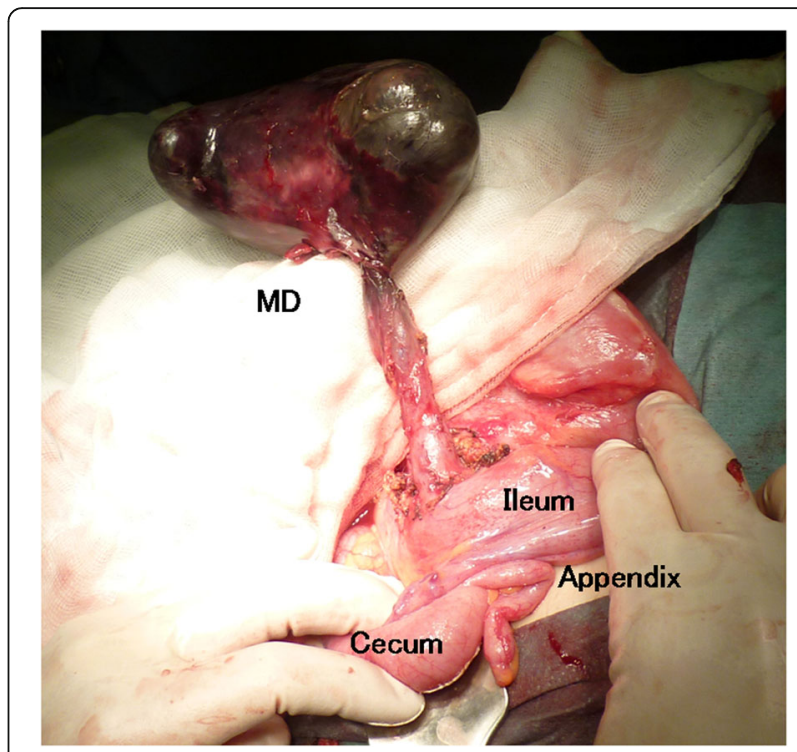

Fig. 2 Intraoperative findings of the axial torsion of Meckel's diverticulum (MD)

remains unclear. On the basis of the several articles, there are several risk factors: primary neoplasms arising within the MD [10], fibrous vitelline bands connected the MD to the abdominal wall [11], and the MD length and width of the base $[8,12]$. The anatomical configuration, especially the diverticular length and base diameter are important predisposing factors. In particular, an elongated variant with a narrowed neck is far more likely to result in torsion [12]. In the case of the patient, the cause of axial torsion of the MD might be the giant head and narrow base as well as the bowel dislocation due to the gravid uterus.

Symptomatic MD is often difficult to diagnose because it mimics acute appendicitis, peptic ulcer, pelvic inflammatory disease, or gastroenteritis. In pregnancy, the diagnosis is even more difficult. The normal physiological and

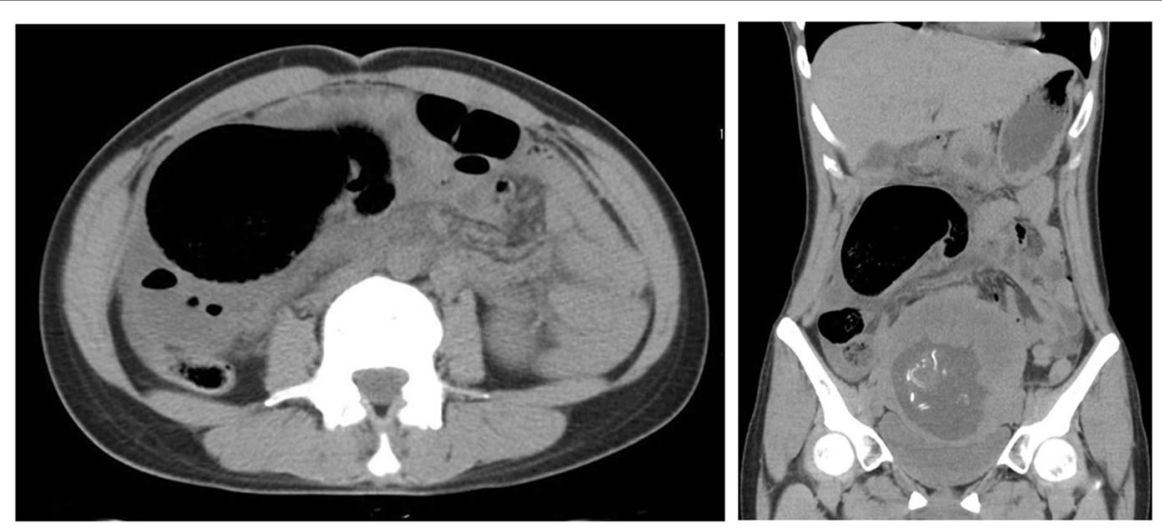

Fig. $1 \mathrm{CT}$ imaging of the abdomen (left, axial view; right, coronal view)In the right mid-abdomen, there was a large air containing cavity connected to the small intestine 


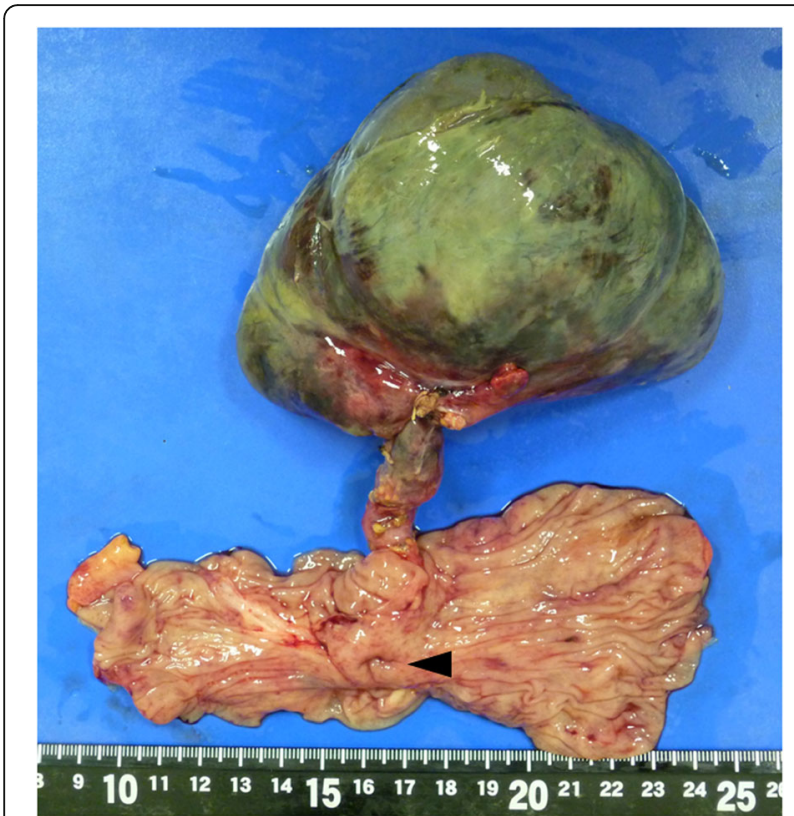

Fig. 3 Gross findings of the resected bowel containing axial torsion of Meckel's diverticulum (MD). The arrowhead reveals the orifice of Meckel's diverticulum (MD)

anatomical changes in pregnancy complicate the evaluation of acute abdomen. Normal symptoms of pregnancy like nausea, vomiting, abdominal, and pelvic discomfort overlap with the symptomatology of non-obstetric causes of acute abdomen. Many examination findings are altered as the gravid uterus displaces the other intra-abdominal organs, and signs of peritonitis may be absent due to lifting and stretching of the anterior abdominal wall. Leucocytosis, anemia due to hemodilution and tachycardia are normal findings in pregnancy. Therefore, imaging investigations for acute abdomen in pregnancy are important. Ultrasonography is the first-line imaging investigation for acute abdomen in pregnancy, though it has limited diagnostic capabilities in a pregnant patient with acute abdomen. The most useful diagnostic modality is CT examination [4], as can also be seen in the present report. $\mathrm{MD}$ is difficult to distinguish from the normal small bowel in uncomplicated cases on CT examination. However, a blind-ending fluid or gas-filled structure in continuity with the small bowel may be seen [13]. In this case, CT findings supported the emergency laparotomy even though radiation exposure by a CT scan is a major concern and the risks and benefits should be evaluated. The absolute risk of fetal effects is small at conceptus doses of $100 \mathrm{mGy}$ and negligible at doses of less than 50 mGy [14]. CT examination of abdomen and pelvis rarely exceed 25 mGy. CT examination may be appropriate depending on the clinical situation, because the dose from a single-acquisition CT examination of the abdomen and pelvis poses a small risk to fetal health [14].
Surgical resection of symptomatic MD is the standard of care. Surgical options include simple diverticulectomy or ileal resection with the later procedure preferred when there is evidence of severe inflammation, perforation, or tumor [15]. In this case, the ileocecal resection including MD was performed in continuity with the adjacent inflamed intestinum by reason that tumors within the giant MD could not be completely ruled out.

\section{Conclusion}

In view of the non-specific presentation of Meckel's pathology in pregnancy, the management requires a multidisciplinary team approach consisting of a surgeon, an obstetrician and a radiologist in order to achieve a favorable outcome for mother and neonate.

\section{Abbreviations}

AST: Aspartate aminotransferase; CT: Computed tomography; MD: Meckel's diverticulum

\section{Acknowledgements \\ None.}

\section{Authors' contributions}

$\mathrm{HN}$ collected the data and drafted the manuscript. HN and HN performed the operation. YS reviewed the manuscript. All authors read and approved the final manuscript.

\section{Funding}

None of the authors have anything to disclose.

\section{Availability of data and materials}

None.

Ethics approval and consent to participate

Not applicable.

\section{Consent for publication}

Written informed consent was obtained from the patient for publication of this case report and any accompanying images. A copy of the written consent is available for review by the Editor-in-Chief of this journal.

\section{Competing interests}

The authors declare that they have no competing interests.

Received: 5 July 2019 Accepted: 25 November 2019

Published online: 05 December 2019

\section{References}

1. Yamaguchi M, Takeuchi S, Awazu S. Meckel's diverticulum. Investigation of 600 patients in Japanese literature. Am J Surg. 1978;136:247-9.

2. Sagar J, Kumar V, Shah DK. Meckel's diverticulum: a systematic review. J R Soc Med. 2006;99:501-5.

3. Yahchouchy EK, Marano AF, Etienne JC, Fingerhut AL. Meckel's diverticulum. J Am Coll Surg. 2001;192:658-62.

4. Prall RT, Bannon MP, Bharucha AE. Meckel's diverticulum causing intestinal obstruction. Am J Gastroenterol. 2001;96:3426-7.

5. Guss DA, Hoyt DB. Axial volvulus of Meckel's diverticulum: a rare cause of acute abdominal pain. Ann Emerg Med. 1987;16:811-2.

6. Eser $\mathrm{M}$, Oncel $\mathrm{M}$, Kurt N. Gangrene secondary to axial torsion in a patient with Meckel's diverticulum. Int Surg. 2002;87:104-6.

7. Rajesh A, Chandra A. Re: Axial torsion of Meckel's diverticulum. ANZ J Surg. 2019:89:447-9.

8. Limas C, Seretis K, Soultanidis C, Anagnostoulis S. Axial torsion and gangrene of a giant Meckel's diverticulum. J Gastrointestin Liver Dis. 2006; 15:67-8. 
9. Botezatu R, Marian R, Gica N, lancu G, Peltecu G, Panaitescu AM. Axial torsion and infarction of Meckel's diverticulum in the 3rd trimester of pregnancy. Chirurgia. 2018;113:266-9.

10. Almagro UA, Erickson L Jr. Fibroma in Meckel's diverticulum: a case associated with axial and ileal volvulus. Am J Gastroenterol. 1982;77:477-80.

11. Moore GP, Burkle FM Jr. Isolated axial volvulus of a Meckel's diverticulum. Am J Emerg Med. 1988;6:137-42.

12. Tan YM, Zheng ZX. Recurrent torsion of a giant Meckel's diverticulum. Dig Dis Sci. 2005:50:1285-7.

13. Elsayes $\mathrm{KM}$, Menias $\mathrm{CO}$, Harvin HJ, Francis IR. Imaging manifestations of Meckel's diverticulum. AJR Am J Roentgenol. 2007;189:81-8.

14. Torres-Villalobos GM, Kellogg TA, Leslie DB, Antanavicius G, Andrade RS, Slusarek B, Prosen TL, Ikramuddin S. Small bowel obstruction and internal hernias during pregnancy after gastric bypass surgery. Obes Surg. 2009;19: 944-50.

15. Park JJ, Wolff BG, Tollefson MK, Walsh EE, Larson DR. Meckel diverticulum: the Mayo Clinic experience with 1476 patients (1950-2002). Ann Surg. 2005; 241:529-33.

\section{Publisher's Note}

Springer Nature remains neutral with regard to jurisdictional claims in published maps and institutional affiliations.

\section{Submit your manuscript to a SpringerOpen ${ }^{\circ}$ journal and benefit from:}

- Convenient online submission

- Rigorous peer review

- Open access: articles freely available online

- High visibility within the field

- Retaining the copyright to your article

Submit your next manuscript at $\boldsymbol{\nabla}$ springeropen.com 